\title{
Self-efficacy and Online Language Learning: Causes of Failure
}

\author{
Phuttharaksa Yantraprakorn \\ School of Liberal Arts, King Mongkut's University of Technology Thonburi, Bangkok, Thailand \\ Pornapit Darasawang \\ School of Liberal Arts, King Mongkut's University of Technology Thonburi, Bangkok, Thailand \\ Pamararat Wiriyakarun \\ School of Liberal Arts, King Mongkut's University of Technology Thonburi, Bangkok, Thailand
}

\begin{abstract}
The study reported in this article examined why some highly efficacious learners failed in an online foreign language course based on Bandura's theory of self-efficacy. The study was conducted as part of a project investigating the self-efficacious foreign language learners in an online writing course. The motivation behind the study was that the success rate of online learning in Thailand is low. The learning performance of six highly efficacious distance language learners at a recognised English language tutorial school in Bangkok, Thailand was analysed. The data collection included an online questionnaire and individual telephone interviews. The findings suggested that goal setting, shift of attribution and insufficient feedback are factors that might decrease the efficacy of online learners' and affect their decision to withdraw from a program. The implications of this study provide recommendations on support to help online language learners succeed.
\end{abstract}

Index Terms—self-efficacy, online language learning, performance, goal orientation, attribution

\section{INTRODUCTION}

Distance learning has become widespread in world education (Harper, Chen, \& Yen, 2004). Distance learning, which follows the model of online course, is a useful form of education for students (Butler-Pascoe, 1997). This mode of learning is flexible and valuable for learners. It aims to provide opportunities for students to make decision on, control, and assess their own learning independently outside a traditional classroom setting and it leads to lifelong learning (Olson \& Wisher, 2002; Richardson \& Swan, 2003). Consequently, the learners are able to study their selected learning courses at home. Thus, this learning mode is widely used in many countries including Thailand.

For online learning in Thailand, quality and equity in education are key principles of the Ministry of Education (Ministry of Education Thailand. Ministry profile: vision and mission, 2010). Based on the key principles of education, Thai people in all areas would have an equal chance for education regardless of their economic status (Thai Cyber University, 2004). Thai education nowadays uses online technologies to support teaching and learning. Due to the demand of students to learn more at their own time and pace, many institutions offer distance education by using various technologies to provide online learning courses. Those courses offer students educational opportunities and the flexibility of when and where they access their courses. Because of the accessibility and lower costs, education institutions adopted the Internet and used it as the tools to reach many students around the country (Wattanapanit, 2015). Consequently, the students are able to study their selected learning courses at home. Thus, this learning mode is widely used in many disciplines including English language learning.

Online learning is popular throughout the world. However, in Thailand, Tanchaisak (2015) pointed that the success rate of online learning is quite low. While online distance learning is popular, its effectiveness was still remained questionable. Despite the increasing enrolment percentages, the online learners drop out of the course. It was found that they fail to complete their courses. This is an important problem for distance learning educators. To reduce the dropout rate and ensure the development in online courses, it is important to conduct a research to understand the changing behaviours of online learners as understanding the learners may help the educators provide the practical support of online learning.

Online learners' failures or dropout have received much attention from educators because the dropout rate is an indicator of the success of an online course (Willging \& Johnson, 2004). Based on a learner-centered nature of distance learning, a considerable number of studies on online learning failure have paid attention to learner related factors. Legault, Green-Demers, and Pelletier (2006) studied why high school learners lacked motivation and found those learners' beliefs about not being able to complete a task or low-ability beliefs were associated with intentions to drop out. Research has revealed that learners' self-beliefs are strong predictors of academic achievements so educational psychologists are calling for attention to learners' self-beliefs related to their academic pursuits (Pajares, 1997). Of all the beliefs, self-efficacy belief seems to have the most influential power in human agency and helps explain why 
people's behaviours differ widely when they have similar knowledge and skills (Bandura, 1986). Hardré, Sullivan, and Crowson (2009) studied learners' characteristics and motivation especially perceived competence or self-efficacy and they found perceived self-efficacy had a direct impact on intention to success. Therefore, self-efficacy is one of the factors that are linked to dropout. Nonetheless, despite an interest in the learners' self-efficacy and their effects on the distance learners' learning, no study has considered self-efficacious learners who dropped out. Hence, understanding self-efficacious learners' experience of participation in the course as well as their problems and then finally reason for dropping out is considered essential. Thus, this study aims to provide an insightful explanation of experience, which highly efficacious learners go through before they decide to drop out.

\section{LITERATURE REVIEW}

\section{A. Self-efficacy Theory}

Self-efficacy, a personal belief in one's capability to organise and execute courses of action required to attain designated types of performances, has its origins in Bandura's (1977) social cognitive theory. The concept recognises the powerful influence of self-efficacy on human cognition, motivation, and behaviour (Ouweneel, Le Blanc, \& Schaufeli, 2013). According to Bandura (1997), levels of self-efficacy come from four sources: mastery experiences, vicarious experience, social persuasion, and physiological states. The first source of self-efficacy is the learners' successful experiences or mastery experiences that influence their beliefs about their abilities and lead to greater feelings of self-efficacy. Mills, Pajares, and Herron, (2007) note that students' self-efficacy beliefs strongly affect their academic performance in many ways. Students with high levels of self-efficacy are willing to carry out challenging tasks, expend greater effort, show increasing persistence in the presence of difficulties, and experience lower anxiety levels. Therefore, previous studies have been investigated self-efficacy as an essential affective factor and a predictor that relates to academic achievement (Komarraju \& Nadler, 2013; Putwain, Sander, \& Larkin 2013; Tilfarlioğlu \& Cinkara, 2011).

\section{B. Self-efficacy and Online Learning}

Self-efficacy theory has specific importance to online learning. Puzziferro (2008) states that learners' self-efficacy is influenced by personal factors and that the consequential efficacy beliefs affect learners' decision to persevere in an online course. According to learners' self-efficacy and effects on learning in the online environment, the studies over two decades show that self-efficacy is strongly related to online learning and performance (Bolt, Killough, \& Koh, 2001; Tsai \& Tsai, 2003). For example, Tsai and Tsai (2003) explored students' information searching strategies in Web-based science learning activities and further examined the influence of students' Internet self-efficacy on these strategies. The study was carried out with 8 participants who were selected from 73 college freshmen based on mixed genders and Internet self-efficacy levels. The findings of this study indicated that learners with higher Internet self-efficacy perform better than those with lower Internet self-efficacy in the Web-based learning task. Moreover, some studies show a strong and positive impact of efficacy on many aspects of learner motivation and achievement (Joo, Bong, \& Choi 2000). Joo, Bong, and Choi (2000) studied the influence of self-efficacy for self-regulated learning, academic selfefficacy, and Internet self-efficacy on learners' performance in a web-based learning context. This study revealed that computer self-efficacy is an important and influential variable in success with distance learning, which is a type of learning format where the learners and teachers are separated by distance and technology is used to decrease the distance obstacle. Womble (2007) measured the relationships among learner satisfaction, self-efficacy, and usefulness within an e-learning context with 440 government agency employees in the South western United States. The study found a significant positive relationship between computer self-efficacy and learner satisfaction in online learning environments. In addition, Jan (2015) investigated the relationships between academic self-efficacy, computer selfefficacy, prior experience, and satisfaction with online learning with 103 graduate students enrolled in purely online courses at a university in USA. The researcher used online survey and found a positive and significant relationship between computer self-efficacy and prior experience with online learning, and between academic self-efficacy and prior experience with online learning, and between academic self-efficacy and student satisfaction.

Nonetheless, despite the fact that self-efficacy is closely related to success in learning in the online environment, this relationship does not hold for every learner, and there are self-efficacious learners who fail. Hence, understanding selfefficacious learners' experiences when participating in an online course, as well as the problems they face and their reasons for dropping out, is essential. Thus, this study aims to provide insights into the experiences of highly efficacious learners before they decide to withdraw.

Therefore, this study investigated why and how highly efficacious learners failed in an online foreign language course. It focuses on six main aspects that reflect how self-efficacy works in distance language learning: goal orientation, attribution, resilience, self-confidence, strategy, and persistence (Yantraprakorn, Darasawang, \& Wiriyakarun, 2013). Goal refers to the learners' reasons for engaging in the distance language learning course and in a writing task. Goal setting is a powerful process for distance language learning and for motivating the learners to learn by themselves. There are two types of goals: performance and teach (Locke \& Latham, 2002). Attribution refers to the perceptions of success or failure from previous learning experiences while the learners are engaging in distance language learning or tasks. The most commonly inferred causes of success and failure are ability, effort, luck and task 
difficulty (Weiner, 1985). Resilience is defined as the learners' capacity to adapt positively to pressure, setbacks, and challenges to achieve goals. They are behaviours that people use when faced with stresses or setbacks, life events, and external commitments (Kemp, 2002). Self-confidence is a feeling of trust that learners have in their abilities, qualities, and judgements. Strategy refers to the methods that the learners use to engage in distance language learning successfully. Persistence is the action in which learners continue studying until completing the course.

The conceptual framework of this study is based on Bandura's social cognitive theory, which interprets human functioning as a sequence of shared interactions or the product of the dynamic interplay among personal influences (e.g., self-efficacy), environmental features, and behaviours (Bandura, 1986).

\section{THE STUDY}

The purpose of this study is to investigate highly self-efficacious learners when they engage in an online writing programme to answer the research question. 'Why do some highly efficacious learners fail in an online language learning environment?' In this section, we provide a background to the context of the study, participants, instruments, data collection procedures, and data analysis.

\section{A. Context of the Study}

This research study was conducted in a recognised English language tutorial school where distance language learners voluntarily worked on the course outside of their regular schools. Thus, it was expected that the learners were motivated to learn independently. The selected course was an online writing course which allowed learners to practise writing types of essays that are taught at the university level such as the comparison essay and the report. The course content was delivered through pre-recorded streaming video lectures and textbooks. To learn writing online, learners had to access the school website to study the content after registering for the course, paying tuition and fees, obtaining course materials, and getting student ID cards. There were 15 lessons, and each lesson began with an overview of the topic followed by exercises and assignments in the writing and vocabulary books that were related to the content. There were three main stages in the course that were designed to gradually teach the online learners academic writing.

Stage 1: Input session. This stage was intended to teach the learners certain strategies necessary for writing effectively. Each lesson began with an overview of the topic, followed by exercises and assignments in the writing and vocabulary books that were related to the content. The course also provided sample essays to help learners understand the components of good academic writing and writing processes that could be used to complete the writing assignments in stage 3 .

Stage 2: Practice session. After the input session, at the end of each lesson, learners had the chance to gain more practice in employing the writing strategies learned in this course. Here, they selected exercises in the writing and vocabulary books according to their own abilities and interests, after which they checked the possible answers in the videos.

Stage 3: Assignment completion session. In this stage, they performed writing at a higher level than in stage 2. Learners had to complete 9 writing assignments after they demonstrated an understanding of the format through studying the input and completing the exercises. First, learners worked individually after finishing each lesson and completed each assignment by choosing from the provided topic choices. They had to follow the following sequence of tasks: 1: completing an outline, 2: describing graphs, 3: writing an introduction, 4: writing the body, 5: writing the conclusion, 6: writing a process essay, 7: writing a complete essay on a topic from a provided writing prompt, 8: writing a compare and contrast essay, and 9: writing an argumentative essay. After finishing each task, they submitted it to the instructors online to obtain feedback. Feedback was given within a week in the form of correction symbols and written commentary. After the learners completed all of the tasks and course requirements within six months, they obtained a certificate of course completion.

\section{B. Participants and Subject Selection}

The subjects in this study were 114 learners who enrolled in the writing course. They were asked to fill out a webbased questionnaire to assess their self- efficacy level. Then, 6 of those who rated themselves as having high level of self-efficacy were selected as the participants. All of them had high level of self-efficacy (High 2.41-4.00), studied at upper secondary school level, had no experience in distance learning, and were willing to be interviewed. The participants were informed that their involvement in this study was voluntary and that they were free to withdraw at any stage. The six subjects were asked to suggest a pseudonym for themselves that the researchers could use. They are Jim, Pam, Ann, Bell, June, and Kim. Then, the researchers began the data collection. Midway through the data collection period, two participants dropped out of the study, but they responded to the researchers' request for further interviews. As a result, the participants were separated into completers because they completed the writing course within the time provided and non-completers or highly efficacious learners who were regarded as unsuccessful because they could not complete the course. The table 1 shows the demographic data and self-efficacy level of participants who took part in the qualitative part of the study. 
TABLE I

DEMOGRAPHIC DATA AND SELF-EFFICACY LEVEL OF PARTICIPANTS

\begin{tabular}{|l|l|l|l|l|}
\hline Subject/Name & Sex /Age & $\begin{array}{l}\text { Self-efficacy Level } \\
\text { (High 2.41-4.00) }\end{array}$ & Hometown & Status \\
\hline Subject 1/Jim & Male/18 & 3.94 & Chachoengsao & Completers \\
\hline Subject2/Pam* & Female/17 & $\mathbf{3 . 8 2}$ & Bangkok & Noncompleters \\
\hline Subject 3/Ann & Female/18 & 3.94 & Bangkok & Completers \\
\hline Subject 4/Bell* & Female/17 & $\mathbf{3 . 8 2}$ & Kanchanaburi & Noncompleters \\
\hline Subject 5/June & Female/18 & 3.88 & Songkhla & Completers \\
\hline Subject 6/Kim & Female/18 & 4.00 & Chiang-Rai & Completers \\
\hline
\end{tabular}

\section{Instruments}

The research instruments used for data collection were a web-based questionnaire and semi-structured telephone interviews. The web-based questionnaire was used for selecting highly efficacious distance language learners and was administered to the learners before beginning the course to assess their self-efficacy (Yantraprakorn, Darasawang, \& Wiriyakarun, 2013).

Individual telephone interviews served as the main source of information for revealing students' self-efficacy as well as their distance language learning experiences. To validate the instrument, interview questions were piloted with a small group of students. Based on the results of the pilot, minor revisions were made to address instrument validity issues, including rewording and adding or removing questions. All of the interviews were conducted in Thai. They were recorded and transcribed afterwards.

\section{Data Collection Procedures}

After the researchers obtained permission from the school to collect data, the data collection procedures were set systematically and ethically. The participants were debriefed before the administration of the questionnaires to explain the purpose and procedures of the research. The selected participants were given consent forms to fill out before the interviews were conducted.

Data collection was divided into three stages: pre-, while-, and post-learning interviews, which were conducted at different times throughout the study. The interviews were conducted to gather the participants' background information, how they observed themselves as language learners, their past language learning experiences, and their language learning goals. The interviews were also used to explore students' self-confidence, resilience, strategies, attributions and persistence.

\section{E. Data Analysis}

The interview data were coded into 6 main aspects that are indicators of self-efficacy: goal orientation, attribution, resilience, self-confidence, strategy, and persistence. The researcher analysed the keywords that reflect the 6 categories. Goal orientation includes participants' statements about their reasons for engaging in the distance language learning course and in a writing task. 'Attribution' includes participants' statements about the perceptions of success or failure from previous learning experiences. 'Resilience' includes participants' statements referring to their capacity to adapt positively to pressure, setbacks, and challenges to achieve goals. 'Self-confidence' includes participants' statements about a feeling of trust in their abilities, qualities, and judgements. 'Strategy' includes participants' statements referring to the methods that they use to engage in distance language learning successfully. 'Persistence' includes participants' statements about the perseverance of the students in studying until completing the course. To increase the reliability of the qualitative data analysis, an inter-rater reliability check was used. A coder was asked to code $20 \%$ of the transcribed interviews using the same criteria as the researcher, and the Kappa coefficient was 0.86 .

\section{FINDINGS}

The findings relating to the research question is provided. The subjects' self-report on their self-efficacy and performances are presented to answer the research question.

Research question: Why do some highly efficacious learners fail in an online language learning environment?

The interviews data showed that a decreased level of self-efficacy was the major reason for the learners' dropout from the online course, and the main findings of this study highlight the importance of the six indicators of self-efficacy. These indicators consist of goals, attributions, resilience, self-confidence, strategies, and persistence. The indicators are presented in a self-efficacy pattern of highly efficacious distance language learners while engaging in the course in terms of the non-completers; Bell and Pam. Bell lives in Kanchanaburi. Her self-efficacy is 3.82. Although she stood out as the girl with the high level self-efficacy on the quantitative measure, in interviews she is a quiet, self-conscious girl who seems to overthink her answers in the interview. She had been learning English for many years and she felt that her listening, speaking and reading abilities were quite good. She stated that English is one of the languages most required in applying for many university programs, so certifying her English writing level would make her stand out from the other students. Pam lives in Bangkok. She is involved in numerous after-school activities, including playing guitar, swimming, and dancing. Pam is a serious girl, and she takes time after each of questions to consider her answer 
before she speaks. Her self-efficacy is 3.82. She works very hard in school and is proud to earn good grades, and is also proud of her status in the Science-Mathematics program.

In order to ensure a deep understanding of the process of failure, figure 1 illustrates the dynamic change of selfefficacy in distance language learning. Based on the data, withdrawing from the course in this study was a process and did not occur overnight. There were factors that may have led the non-completers to decrease their high level of selfefficacy gradually. The figure shows how the participants approached the online courses.

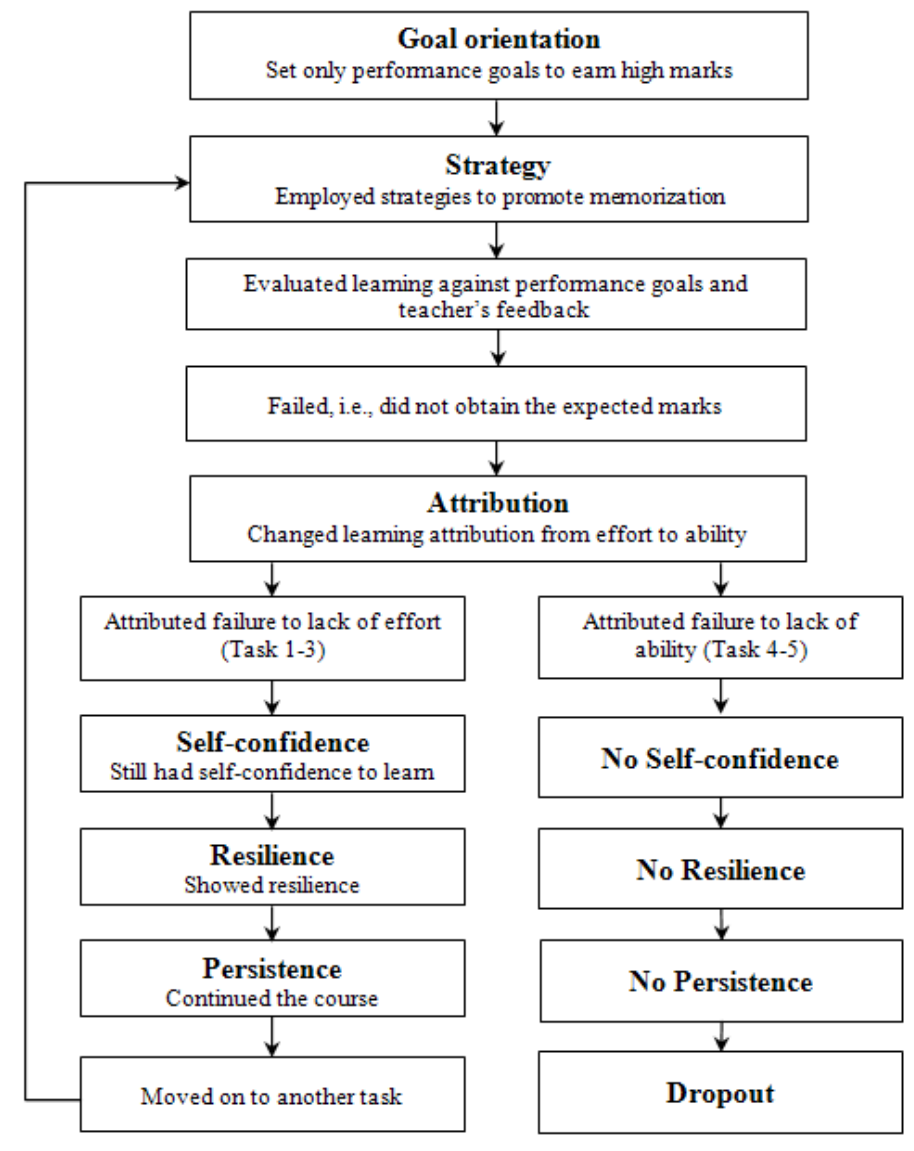

Figure 1. Self-efficacy Pattern: Non-completer

The non-completers started their learning by setting goals to learn (Goal orientation). They emphasized only performance goals to pass the course and to get high scores in order to prove that they have writing ability, while the completers reported using different types of goals to learn. The completers focused more on mastery goals to improve their writing competence. Bell started to learn by setting short term performance goals for herself. Her goals in learning writing online are to study with the famous tutor and to get the best score.

"At the very beginning of the course, I have no idea what this course is going to be about and what activity I am going to do online. The reason I chose this web class was also really simple, one of my friends told me the teacher is the best. She can help me to get good writing scores as I want."

(Bell- Before learning-Performance goal orientation)

Pam, another non-completer, also linked her performance goal with extrinsic motivation to show her ability; i.e. she wanted to get a certificate to please her mother.

"My goal in learning writing online is to get the best score and get a certificate from the school. I think my mother will be satisfied with it."

(Pam - Before learning-Performance goal orientation)

Consequently, setting only performance goals to get the highest scores might have had a negative effect on the noncompleters' distance language learning because they could not finish the course.

In order to achieve their goals, both non-completers and completers reported that they employed many learning strategies to accomplish online writing tasks and to control their own learning (Strategy). The non-completers mentioned more memory strategies to achieve their performance goals; however, those could not assist them to learn successfully. In contrast, completers reported more strategies that supported the metacognitive perspective of selfregulated learners. They used different learning strategies that were systematically directed towards the achievement of their learning goals. They used information seeking, assistance seeking, goal setting and planning, self-evaluating, organizing and transforming strategies. The completers truly wanted to learn and were more likely to use strategies to 
help them to actually master the online writing materials, whereas the non-completers wanted to display competence so they used strategies only to achieve good grades. Bell, for example, chose more memory strategies to learn seen from her extract.

"I attempted to remember unknown words that I learned in the provided vocabulary book by using them in my writing."

(Bell - While learning - Memory strategy)

According to the data, the participants attributed their failures differently (Attribution). The non-completers changed their failure attribution from effort to ability, while the completers attributed their success and failure to their own efforts. At the beginning of the course, the non-completers mostly placed the primary cause of their low marks on their lack of effort, which is a controllable cause as seen from Bell's report:

"I did not study well for this one. I'll just make sure that next time I'll study more and obtain a better score........I understand that the only thing that prevented me from writing my essays as well as I can was the lack of effort. I worked hard to remember new words and practice my writing abilities."

(Bell - While learning - Attribution, lack of effort)

However, after a repeated failure, the non-completers were not motivated to learn because they believed that their repeated failure was due to inability or the causes they could not control, as seen from Bell's extract.

"I think my failure in this course is due to my own inability to learn how to write. My writing score was not good. Although I understood the lesson, I could not apply what I had learned in my writing essay...After putting more effort into my work, the result was still unsatisfactory. The score did not change much even after the third task. The cause is my ability. I think that I will not be able to improve with my next task."

(Bell - Post learning - Attribution, lack of ability)

Pam, the other non-completer, also blamed her inability to learn:

"The scores from the exercises and previous tasks showed what a bad student I am. I think nothing is going to change. Additionally, it means I will be bad at the other tasks in this course as well. I'm not going to do well in the online course".

(Pam- Post learning - Attribution, lack of ability)

Pam also said:

"Recalling what I have learned, it made me understand that the more time I spent, the worse the result would be. I saw the gap between my score compared to other students. My friend is a good learner and writer. I felt bad about my writing ability."

(Pam- While learning - Attribution, lack of ability)

Bell blamed her inability to learn as she reported,

"After putting more effort in my work, the learning result was still unsatisfactory. The mark did not change much even after the third task. The cause is my ability. I think that I will not be able to improve my next task."

(Bell - While learning - Attribution, lack of ability)

They thought that they could not express and write their ideas due to limited language proficiency as seen from Pam' excerpt,

"The general problem for me is I think I ...do not have language ability. I mean I have to write English and I could not express what I think properly."

(Pam- While learning - Attribution, lack of ability)

Therefore, the shift of attribution of their failure may cause the non-completers to give up or dropout. This perception seems to be critical for their distance language learning.

At this stage, they made their own decision as to whether they wanted to continue learning. The non-completers decided to return to the engagement stage with decreased self-efficacy. However, while the completers showed resilience to achieve their mastery goals, in the middle of the course, the non-completers did not show resilience (Resilience) and persistence (Persistence) in their performance. According to their failure attributions, they did not adapt positively to pressure, setbacks, and challenge in order to achieve goals. Pam avoided learning and gave up when difficulties arose. The non-completers believed that they lacked and could never develop the ability to write.

"I realised that writing is a painful process. When writing in English, the problems are greater, even when writing on a simple topic. I hope what I wrote was perfect, but I got low scores over and over again. Writing academic essays... is a problem to me. I am really weak in writing. I feel really tense when I need to write an essay now"... "for me, the major challenge is organizing myself because this is the first time I have taken an online course. All of my online lessons and tasks were messy, and because I have poor language abilities, I decided to quit.”

(Pam- Post learning - Lack of Resilience and Persistence)

"I am not able to study and do well. I am weak in English grammar and writing. .......No, I could not deal with this problem. I tried to solve the problems, but it did not work. Why does this always happen to me!"

(Bell- While learning - Lack of Resilience and Persistence)

Both completers and non-completers evaluated their own learning by checking if they have reached their goals. In this online writing course, the course instructors gave the learners corrective feedback by indicating corrective symbols and let the learners figure out and then correct their works based on the symbols by themselves. Moreover, the non- 
completers viewed errors as a sign of failure and incompetence. The implicit feedback from the instructor may not be sufficient especially in distance learning context where the learners need more scaffolding. The feedback and unsatisfied marks made the non-completers demotivated to achieve their own performance goals, as Pam said,

"I got a low score again, and I was not satisfied with the result of this essay. I got the teacher's feedback, and I had made many grammatical errors. After receiving feedback and a mark that I did not expect, I really felt a sense of failure. I am not sure if I can complete the next task and finish this course."

(Pam- While learning - Lack of Resilience and Persistence)

The implicit feedback from the instructor may not have been sufficient, especially in a distance learning context, where learners need more scaffolding. Pam and Bell also showed a desire to have all their errors corrected. Bell said,

"I got a low score. My teacher did not provide me with the correct answers, and I was not sure what I wrote was correct. Grammar is difficult, and my teacher should have helped me by correcting all my grammatical mistakes."

(Bell- While learning)

Pam also reported that

"I was not given the correct answer, so I spent long time thinking and finding how to correct my errors based on the teacher feedback. I think it is motivating to see feedback on my work that is not only about grammatical errors."

(Pam- While learning)

They saw the indirect corrective feedback as punishment rather than something useful. They preferred written direct feedback because this was easier to understand and they thought they would gain more understanding from the direct feedback.

". I am confused with the feedback; it is like the teacher is punishing me. To study online successfully, I'd like the teacher to correct my work or tell me directly how to do the task because it will be easier to understand, and I think I will gain more knowledge from the feedback."

(Pam- While learning)

The feedback also affected their motivation to learn, as Bell said,

"It took time to correct my errors by checking the key in this online course. I found the feedback confusing. It was complicated, there were so many errors, and I could not correct them myself, such as prepositions and punctuation. I do not know how to use tenses. I had too much feedback on my errors, and I felt discouraged."

(Bell- While learning)

In the middle of the course, the non-completers lacked confidence (Self-confidence) and did not want to participate in learning at a higher level. Lack of confidence in their capabilities had affected their success in the online course. They did not trust themselves to study, and complete the tasks and the course. For example, Pam confessed that she did not feel confident enough to complete the tasks and the course,

"I am not confident that I will to complete the tasks and the course. No matter how much I practice, I am not able to study and do well".

(Pam- Post learning - Lack of self-confidence)

They lacked resilience to learn and then they gave up. They did not try to deal with the problems and no longer persisted to finish the course. This led to weaken their resilience to learn. They did not re-engage in the course and dropped out in the middle of the course and left their tasks undone.

\section{DISCUSSION}

The data from this study showed that factors affecting non-completers' failure may come from two potential sources: inappropriate goal orientation and the shift of their failure attributions.

\section{A. Inappropriate Goal Orientation Led to Ineffective Learning Strategies and Unsuccessful Performance}

According to the data, distance language learning success was not only in setting goals but setting appropriate types of goal. Performance goals focus on how well the learners accomplish the tasks at a particular time, whereas mastery goals focus on how well they finally learn or master the material regardless of how long it may take. Therefore, adoption of both types of goals may promote both short-term and long-term resilience and persistence towards learning writing online. According to the data, the focus on performance not only demotivated the non-completers but also affected their attribution. Pam and Bell did not achieve their performance goals as expected even though the scores they obtained were not lower than those of the completers. They interpreted failure as a sign of low ability, and they also viewed the teacher's feedback or their own errors as a sign of failure and incompetence, which in turn affected their confidence to learn successfully, and they finally they gave up attempting to complete the course. Moreover, the completers who had mastery goal were able to engage in more effective learning strategies than the non-completers who had performance goal. They reported that they had minimal self-regulated learning strategies for writing The noncompleters wanted to display competence so they used strategies only to achieve good grades, whereas the completers truly were more likely to use strategies to help them to actually master the materials. Therefore, the development of a learning goal orientation was required for improving distance language learning because it affected the learners' longterm performance and learning strategy. 


\section{B. Lack of Mastery Experiences and the Insufficient Feedback Led to a Shift of Attribution, Low Resilience and Decrease of Self-efficacy, Self-confidence and Persistence}

The participants' failure occurred when the non-completers, who had high levels of self-efficacy to complete the online course before learning, gave up attempting because of consistent failure to achieve their performance goals. Bandura (1986) stated that performance accomplishment is influential because individuals can relate it to their mastery experiences. Lack of mastery experience affected their self-efficacy because after attempting many times to obtain the expected marks and failing, they began to feel that failure was inescapable. This led to negative learning performance and its effects (e.g., lack of resilience and self-confidence).

After encountering failures repeatedly or experiencing a lack of mastery experiences, the non-completers decreased their level of self-efficacy and shifted their failure attributions from a lack of effort to a lack of ability. This was a cause for setbacks, which made the attribution destructive. There were dimensions of attribution that related to academic performance: locus of control and stability dimensions (Weiner, 1985). The dimensions of locus of control help to explain the consequences of attributions whether the locus is under a person's control because it is related to the intensity of a performer's personal emotions (Weiner, 1985). The stability dimension refers to whether the causes the learners give for their success or failure were relatively stable or unstable over time. Ability is seen as a stable factor because it does not change. The non-completers attributed their failure to lack of ability, so they expected failure in similar tasks in the future. Therefore, a stable cause such as a lack of ability affected the way they approached their future tasks, resulting in learned helplessness. In this study, Pam and Bell were not motivated to learn because they believed that their experiences of repeated failures were due to causes out of their control. Bell blamed her inability to learn. The excerpt from Bell reveals that failure attribution played a role in forming future confidence expectations. The mastery experience was a critical source of self-efficacy. Based on these findings, the non-completers blamed themselves for failure; they believed that they had low ability and viewed their limited language proficiency and teacher's feedback as confirmation of this belief.

In addition, a possible factor that caused the non-completer to attribute their failure to ability might be the lack of satisfaction in the teacher's feedback. In this study, the teacher gave the learners feedback by coding the errors that the learners produced and identifying the types of errors (e.g., subject-verb agreement). This type of feedback required the learners to mentally process the errors and make a correction by reviewing the grammar rules they had previously learned. According to the data, indirect feedback may not be appropriate for the non-completers who had the performance goals of obtaining high scores and viewed errors as a sign of failure and incompetence.

To further clarify why some highly efficacious learners failed in the online foreign language course, Bandura's social cognitive theory is used to summarise their learning performance. According to Bandura's reciprocal determinism model, distance language learning performance can be explained by a dynamic and reciprocal interaction between personal factors, behaviours, and environment. Figure 2 illustrates that a decreased level of self-efficacy may be caused by internal and external factors such as consistent failure and lack of appropriate goals.

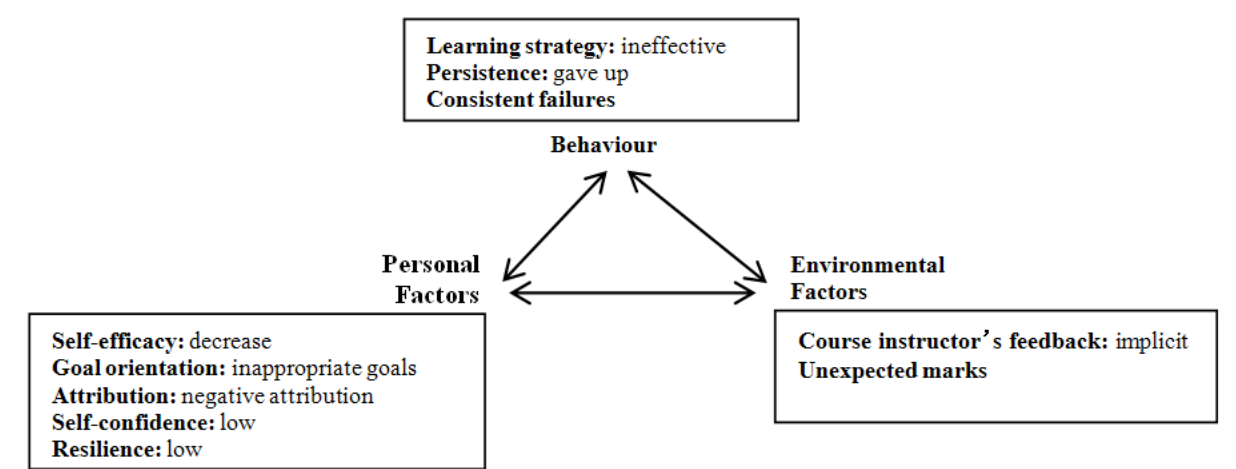

Figure 2. The reciprocal relationship between personal factors, environmental factors and behaviour of the non-completers

According to Figure 2, the reciprocal relationship of the three factors can be exemplified by the findings of the noncompleters whose personal factors showed that they were self-efficacious and highly motivated before learning (Personal factor). They set the inappropriate goal of obtaining high scores and focused only on scores. The goals led them to employ more memory strategies (behaviour); however, these strategies could not help them learn successfully. The strategies led to unexpected marks and lack of satisfaction in the teacher's feedback (Environmental factor). The marks and the feedback affect their learning attribution, self-efficacy, self-confidence and resilience (personal factor). Based on their performance goals to obtain high scores, they interpreted their learning as a failure and then developed negative attribution. They shifted their learning attribution from lack of effort to lack of ability. They attributed the unexpected scores to their inability to learn writing. The perceptions of failure from previous learning experiences demotivated them and may have caused the students to have low self-efficacy, self-confidence and resilience. These personal factors affected their learning persistence (Behaviour) and led them to withdraw in the middle of the course. The findings of this study suggest that learning behaviour or performance depends not only on self-efficacy beliefs but 
also on feedback and on the behaviour itself. Therefore, according to Bandura (1997), the decreased levels of the learners' self-efficacy may come from mastery experiences, and social persuasion. The findings of this study suggest that mastery experiences and social persuasion have an important influence on distance language learners' self-efficacy and their learning performance.

\section{Pedagogical Implications}

The findings of this study seem to suggest that learners still need support even though they were identified as highly efficacious learners. The results of this study about online learners' self-efficacy in Thai online learning environments may help the educators provide the practical support of online learning based on the key principles of Thai Ministry of Education. The findings of this study suggest two ways of maintaining or developing a strong sense of self-efficacy of distance language learners: mastery experience can be enhanced through learning goal-orientation, and effort attribution can be maintained through social persuasions or sufficient feedback.

\section{A. Mastery Experience Can Be Enhanced through Mastery Goal Orientation}

This study found that lack of mastery experience affected participants' self-efficacy. As mentioned earlier, the experience of mastery or performance accomplishment is the strongest and most durable contributing factor of selfefficacy. Enhancing mastery experiences or performance accomplishments can be attained through having an appropriate goal orientation because perceptions of self-efficacy are partly based on the result of goal completion. To maintain or enhance learners' self-efficacy, the instructor may divide up tasks into smaller steps to ensure that the first step includes a task that the students can do so that they experience success early, which can help maintain or increase their self-efficacy. Although the learners need challenging work to learn, failure may set in quickly if the learners do not experience frequent success. The instructor should provide scaffolding when needed.

In addition, according to the findings of this study, it is important to help the learners acquire distance language learning skills in order to complete their online writing tasks. In this study, the learning strategies that the noncompleter possessed and employed in their learning were not sufficient for them to learn by themselves and to deal with the writing tasks because they did not have any online language learning experiences. This might have led to the decrease in their self-efficacy. Therefore, online learners need to be supported and trained in necessary learning strategies to be able to successfully engage in an online learning context.

\section{B. Effort Attribution Can Be Maintained through Social Persuasion or Sufficient Feedback}

This study illustrated that the shift of their attributions may be the essential reason why they failed in the course and led them to unsuccessful learning performance. According to the data, the non-completers blamed themselves for their failures and viewed their errors as an indicator of inability. They also responded negatively to failure and instructor feedback. In fact, indirect corrective feedback is helpful in assisting learners through a discovery procedure and may result in deeper learning. However, in this study, the instructors provided feedback in the form of marking errors with the expectation that students would self-correct, but the non-completers did not understand the errors.

To avoid learner confusion and enhance self-efficacy, instructors should understand the strengths and weaknesses of types of feedback familiarise learners with the feedback they are giving, and make it clear to students what the feedback means and what they are expected to do with it. Therefore, with online learners, feedback should be clear, and all incorrect responses should be accompanied by informative feedback, not simply a corrective symbol. Feedback should be optional as the learner becomes more experienced and more proficient. The instructor may provide an online tool as a set of tutorials teaching the basics of self-correction. Each tutorial could be provided through data files so that the learners are able to follow the tutorials at their own pace.

Sufficient feedback should be used to assist learners in maintaining their self-efficacy beliefs by attributing their successes and failures to the correct causes, especially in online writing courses. Initially, feedback should be frequent to ensure that learners have early positive experiences. Moreover, the instructor should assist the learners in viewing errors as a natural part of the learning achievement process and acknowledge that repeating previous mistakes is not uncommon in language writing.

Teachers can exploit this to promote learning by focusing on effort as the critical factor for success. Therefore, the teacher may help the distance language learning understand that their academic performance is due primarily to factors that they can control and improve. Thus, instructors should provide learners with feedback linking learning result with effort because this attribution is under the learner's control, which can help them develop self-efficacy beliefs and enhance performance. Moreover, the teacher may help the learners understand that lack of ability is not the problem because the problem lies in using an ineffective strategy to motivate themselves to learn. They should be trained to find a better strategy motivating themselves to learn.

In conclusion, this study attempted to explain why some highly efficacious learners failed in an online foreign language course and the factors that influenced the learners' decision to withdraw from the course based on Bandura's theory of self-efficacy. The findings of this study showed that a decreased level of self-efficacy was the major reason for learner dropout. This might have come from changes in learning attributions and the types of goals they set for themselves, which lowered their self-efficacy levels. This study also recommends support tools that can be incorporated 
into an online language learning environment to help students develop knowledge by themselves and increase their selfefficacy for lifelong learning experiences in an online environment.

\section{REFERENCES}

[1] Bandura, A. (1977). Social learning theory. New York: General Learning Press.

[2] Bandura, A. (1986). Social Foundations of Thought and Action: A Social Cognitive Theory. Englewood Cliffs, NJ: PrenticeHall.

[3] Bandura, A. (1997). Self-efficacy: The exercise of control. New York: W.H. Freeman and Company.

[4] Bandura, A. (2002). Social cognitive theory in cultural context. Journal of Applied Psychology: An International Review. 51, 269-290.

[5] Bolt, M., Killough, L., \& Koh, H. (2001). Testing the interaction effects of task complexity in computer training using the social cognitive model. Decision Sciences, 32.1, 1-20.

[6] Butler-Pascoe, M.E. (1997). Technology and second language learners. American Language Review. 1.3, 20-22.

[7] Hardré, P., Sullivan, D. \& Crowson, H. (2009). Student characteristics and motivation in rural high schools. Journal of Research in Rural Education. 24.16, 1-19.

[8] Harper, C. H., Chen, K. \& Yen, D. C. (2004) Distance learning, virtual classrooms, and teaching pedagogy in the Internet environment, Technology in Society. 26, 585-598.

[9] Jan, S. (2015). The Relationships between Academic Self-Efficacy, Computer Self-Efficacy, Prior Experience, and Satisfaction with Online Learning. American Journal of Distance Education, 29.1, 30-40. https:/doi.org/10.1080/08923647.2015.994366.

[10] Joo, Y., Bong, M., \& Choi, H. (2000). Self-efficacy for self-regulated learning, academic self-efficacy, and Internet selfefficacy in Web-based instruction. Educational Technology Research and Development. 48.2, 5-17.

[11] Kemp, W. C. (2002). Persistence of adult learners in distance education. The American Journal of Distance Education. 16.2, 65-81.

[12] Komarraju, M. \& Nadler, D. (2013). Self-efficacy and academic achievement: Why do implicit beliefs, goals, and effort regulation matter? Learning and Individual Differences, 25, 67-72.

[13] Legault, L., Green-Demers, I., \& Pelletier, L. G. (2006). Why do high school students lack motivation in the classroom? Toward an understanding of academic amotivation and the role of social support. Journal of Educational Psychology. 98, 567582.

[14] Locke, E.A., \& Latham, G.P. (2002). Building a practically useful theory of goal setting and task motivation: A 35-year odyssey. American Psychologist, 57, 705-717.

[15] Mills, N., Pajares, F., \& Herron, C. (2007). Self-efficacy of College Intermediate French Students: Relation to Achievement and Motivation. Language Learning. 57.3, 417-442.

[16] Ministry of Education Thailand. Ministry profile: Vision and mission. http://www.en.moe.go.th/index.php?option=com_content\&view=article\&id=19\&Itemid=54 (accessed 21/4/2014).

[17] Olson, T. \& Wisher, R. (2002). The Effectiveness of Web-Based Instruction: An Initial Inquiry. The International Review of Research in Open and Distributed Learning. 3.2. Athabasca University Press. https://www.learntechlib.org/p/49740/ (accessed 27/2/2008).

[18] Ouweneel, E., Le Blanc, P. M., \& Schaufeli, W. B. (2013). Do-it-yourself: An online positive psychology intervention to promote positive emotions, self-efficacy, and engagement at work. Career Development International. 18.2, 173-195.

[19] Pajares, F. (1997). Current directions in self-efficacy research. In M. Maehr \& P. R. Pintrich (Eds.), Advances in motivation and achievement (vol. 10). Greenwich, CT: JAI Press.

[20] Putwain, D., Sander, P. \& Larkin, D. (2013). Academic self-efficacy in study-related skills and behaviours: Relations with learning-related emotions and academic success. British Journal of Educational Psychology, 83.4, 633-650.

[21] Puzziferro, M. (2008). Online Technologies Self-Efficacy and Self-Regulated Learning as Predictors of Final Grade and Satisfaction in College-Level Online Courses. American Journal of Distance Education. 22.2, 72-89.

[22] Richardson, J. C., \& Swan, K. (2003). Examining social presence in online courses in relation to students' perceived learning and satisfaction. Journal of Asynchronous Learning Networks. 7.1, 68-88.

[23] Tanchaisak, K., (2015). The Management of International Online Distance Learning Program in Thailand. http://docplayer.net/6296796-The-management-of-the-international-online-distance-learning-program-in-thailand.html (accessed 20/3/2017).

[24] Thai Cyber University. History of the TCU. (2004). http://lms.thaicyberu.go.th/OfficialTCUen/main/main2.asp (accessed 28/3/2017).

[25] Tilfarlioğlu, F. T., \& Ciftci, F. S. (2011). Supporting Self-efficacy and Learner Autonomy in Relation to Academic Success in EFL Classrooms (A Case Study). Theory and Practice in Language Studies. 1.10, 1284-1294. http://dx.doi.org/10.4304/tpls.1.10.1284-1294. (accessed 5/5/2016).

[26] Tsai, M. J. \& Tsai, C. C. (2003). Information searching strategies in web-based science learning: The role of Internet selfefficacy. Innovations in Education and Teaching International, 40, 1, 43-50.

[27] Wattanapanit, N., 2015, The Students' Perceptions toward Ramkhamhaeng University Blended Distance Learning. https://linc.it.edu /linc2013/proceedings/Session6/Session6Wattanapanit.pdf (accessed 20/3/2017).

[28] Weiner, B. (1985). An attributional theory of achievement motivation and emotion. Psychological review. 92.4, 548.

[29] Willging, P. A., \& Johnson, S. D. (2004). Factors that influence students' decision to dropout of online courses. Journal of Asynchronous Learning Networks. 8.4, 105-118.

[30] Womble, J.C. E-learning: The relationship among learner satisfaction, self-efficacy, and usefulness. Ph.D. thesis, Alliant International University, San Diego. 
[31] Yantraprakorn, P., Darasawang, P., \& Wiriyakarun, P. (2013). Enhancing Self-efficacy Through Scaffolding. Proceedings from FLLT 2013: The 3rd International Conference on Foreign Language Learning and Teaching, Bangkok, Thailand. http://www.litu.tu.ac.th/journal/FLLTCP/Proceeding/284.pdf (accessed 28/3/2014).

Phuttharaksa Yantraprakorn is a part-time lecturer at King Mongkut's University of Technology Thonburi (KMUTT). She is currently studying $\mathrm{PhD}$ in Applied Linguistics at KMUTT.

Pornapit Darasawang is Vice President for Internationalisation, King Mongkut's University of Technology Thonburi.

Pamararat Wiriyakarun is a lecturer at the Department of Language, School of Liberal Arts, King Mongkut's University of Technology Thonburi. 